\title{
A comparison of adoption and service quality between large and small broadband internet service providers in Thailand
}

\author{
Kanokkarn Snae Namahoot ${ }^{\mathrm{a}^{*}}$ and Viphasiri Jantasri ${ }^{\mathrm{b}}$
}

${ }^{a}$ Faculty of Business Economics and Communications, Naresuan University, Thailand

${ }^{b}$ Faculty of Business Administration, Institute of Entrepreneurial Science Ayothaya, Thailand

\section{CH R O N I C L E}

Article history:

Received: December 25, 2020

Received in revised format:

April 242021

Accepted: April 24, 2021

Available online:

April 24, 2021

Keywords:

Service quality

Attitude

Technology acceptance and inten-

tion to use broadband internet,

SEM, Thailand

\section{A B S T R A C T}

This research aims to compare the influence of service quality on intention to use broadband internet through attitudes and technology acceptance, as mediator variables between large and small broadband internet service providers (ISPs) in Thailand. A comprehensive review of the literature has modified the development of this behavioral model that explains intention to use of broadband internet. A data set from two groups: large and small broadband ISPs, nationwide survey was conducted in Thailand ( $\mathrm{n}=928$ consumers). The theoretical model was tested using structural equation modeling. The findings show that integrated models have good explanatory power ( 78.3 percent) to predict customer's intention to use broadband internet. The results of this study are as follows. Firstly, service quality: tangible, reliability, responsiveness, assurance and empathy, supports second-order factor analysis. Service quality has an influence on attitude, perceived usefulness, perceived ease of use, and intention to use broadband internet both two types of service providers. Secondly, perceived usefulness has a significant effect on attitude, and intention to use only in small companies. Thirdly, attitude, perceived usefulness, and perceived ease of use as mediator variables have a positive effect between service quality and intention to use broadband internet. This study proposes customer acceptance on broadband internet using a modified TAM.to reveal the impact of service quality on intention to use. The results of this study can be replicated and extended to ASEAN countries. The conclusions and implications for management provide alternatives for companies to increase the number of internet users in order to improve overall quality of life.

(C) 2021 by the authors; licensee Growing Science, Canada

\section{Introduction}

In 2019, Thai population is more than 66.4 million, approximately 47.5 million or $71.5 \%$ are internet users. In the past nine years, the number of internet users has increased by more than $150 \%$. If considering the number of hours, Thais used the internet for an average of 10 hours and 22 minutes a day, increased 17-minute from 2018. LGBT spent time on the Internet the most, for 11 hours and 20 minutes. Among different generations, generation Y (19-38 years) used the internet the most, they surfed an average 10 hours 36 minutes. Surprisingly, it was found that self-employed, business owners, house husbands / housewives, students or even the unemployed used the internet for more than 10 hours. While internet users in all regions, they likely used the Internet tentatively more than 10 hours a day (Electronic Transactions Development Agency, Ministry of Digital Economy and Society, 2020). Internet usage behavior is consistent with the forecast value of e-Commerce in Thailand from 2016 to 2019 approximately 2.5 trillion baht, 2.7 trillion baht, 3.7 trillion baht and 4.0 trillion baht. If consider the forecast value of e-Commerce in Thailand only in 2019, it could be divided into B2B groups of approximately 1.9 trillion baht, B2C groups about 1.4 trillion baht and B2G groups about 0.6 trillion baht (Electronic Transactions Development Agency, Ministry of Digital Economy and Society, 2020). In the situation of Coronavirus (COVID-19), a new virus (World Health Organization, 2020), the government decided to set lockdown restrictions. People had to stay at home for their safety. Therefore, many Thais worked and studied from home. Consequently, Thais used the internet more, the consumption of media from online applications such as Facebook, YouTube, Instagram, Twitter and Tik Tok has raised. These days, Thais use the internet more. Thus, both large and small domestic broadband ISPs highly and continuously attract their customer's attention * Corresponding author.

E-mail address: kanokkarnn@nu.ac.th (K. S. Namahoot) 
to use their services (intention of use) as much as possible. The first priority of the strategy is to deliver quality services to customers. The most commonly used to measure service quality was SERVQUAL, developed by Parasuraman. In 1985 and 1988, service quality was created to measure consumer perception of service quality. (Parasuraman et al., 1985 and 1988). Secondly, the measurement of the adoption of new technology is so called the technology acceptance model (TAM), developed by Davis in 1989 to predict user acceptance of technology (Davis, 1989). Lastly, the study of attitude toward the behavior in theory of planned behavior, was developed by Ajzen in 1991 to predict human behavior (Ajzen, 1991). This study had four objectives. Firstly, this research concentrated on developing countries like Thailand. Because past studies have shown that research in service quality, attitude, technology acceptance and the intention to use the service, they usually focused on developed countries. Secondly, this research examined the influence of service quality, attitude, and technology acceptance. Thirdly, this research aimed to explore the influence of service quality on broadband internet intention to use through attitudes and technology acceptance, as mediator variables. Lastly, this research intended to compare the influence between large and small broadband ISPs in Thailand. The results of this study can be replicated and extended to other countries in ASEAN. The number of internet users increases consequently it improves overall quality of life.

\section{Literature review}

The perception of quality implies the consideration or judgment of the consumer regarding the overall excellence or superiority of a product (Zeithaml, 1988, pp.3). Therefore, on the basis of Zeithaml (1988), the perceived services' quality represents the eminence or supremacy of the service that the consumer receives. Attitude toward intention to use technology indicates the degree of a positive or negative opinion of the technology to be used. Past studies had shown the relationship between service quality and attitude. For example, Carlson and O'Cass (2010) found that perceptions of service quality had a positive influence on attitude. Boisvert and Ashill (2011) found that perception of extended service quality affected attitude. Mansour et al. (2016) discovered that service quality positively affected the attitude of ATM and Mobile Banking customers, but it did not affect customers using the service, internet Banking. Based on the above correlation, past researches had not been found much.

This research examined the context of the broadband internet industry. As following hypotheses were developed.

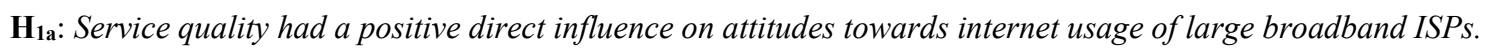

$\mathbf{H}_{\mathbf{1 b}}$ : Service quality had a positive direct influence on attitudes towards internet usage of small broadband ISPs.

Studies related to service quality mostly reviewed expectations as a belief about anticipated traits as a standard for evaluation (Seth et al., 2005: 921). The perception showed belief of a person using a particular system that it will improve his performance. A perceived ease of use indicated the degree of belief of people using a distinct approach that they would not make both physical and mental effort (Davis, 1993: 477). Previous studies showing a correlation between service quality and TAM in terms of perceived usefulness, such as Venkatesh and Davis (2000), found that quality affected the perceived usefulness. Jang and Noh (2011) found that service quality in terms of pattern, well-being and customer service had an opposite effect on perceived usefulness.

On the other hand, Zhu et al. (2012) found that service quality had no influence on perceived usefulness. Meanwhile, former researches showing a correlation between service quality and TAM in the perceived ease of use, such as Jang and Noh (2011), found that quality of term of pattern, well-being and customer service had positive direct impact on perceived ease of use. Zhu et al. (2012) showed that service quality influenced perceived ease of use. Based on the above relationship, previous researches had not been found. Therefore, this research in the context of the broadband internet industry developed the following hypotheses:

$\mathbf{H}_{2 \mathrm{a}}$ : Service quality had a positive direct influence on perceived usefulness of large broadband internet service providers.

$\mathbf{H}_{2 \mathbf{b}}$ : Service quality had a positive direct influence on perceived usefulness of small broadband internet service providers.

$\mathbf{H}_{3 \mathbf{a}}$ : Service quality had a positive direct influence on perceived ease of use of large broadband internet service providers.

$\mathbf{H}_{\mathbf{3} \mathbf{b}}$ : Service quality had a positive direct influence on perceived ease of use of small broadband internet service providers.

The Technology Acceptance Model (TAM) is one of the most used models to study information technology acceptance (Mansour et al., 2016: 247; Pikkarainen et al., 2004). Empirical studies revealed that TAM helped to explain the acceptance of new information technologies (Zhu et al., 2012: 965). This includes forecasting attitude (Jang \& Noh, 2011, pp. 584) towards information technology. TAM indicated that both perceived usefulness and perceived ease of use were important independent variables that could be directed or influenced on attitude (Lin et al., 2011: 273).

Late studies had shown a relationship between TAM in terms of perceived usefulness and attitude, such as Hassanein and Head (2007) Huh et al. (2009), Jang and Noh (2011), Chang et al. (2012). Bashir and Madhavaiah (2015), Mansour et al. (2016), Rahi et al. (2017) as well as Li et al. (2017), figured out that perceptions affected attitude. In contrast to studies of Lin et al. (2011), Nath et al. (2013) all noticed that perceived usefulness did not affect attitude. Past researches had shown a relationship between TAM in the perceived ease of use and attitude, as well as analyses of Huh et al. (2009) Lin et al. (2011). 
Chang et al. (2012), Nath et al. (2013), Bashir and Madhavaiah (2015), Al-Hujran et al. (2015), Mansour et al. (2016), Rahi et al. (2017), Li et al. (2017) detected that the perceived ease of use affected attitude.

On the contrary, Jang and Noh (2011) found that the perceived ease of use had no effect on attitude. These relationships were found not very clear. Thus, this research, in the context of the broadband internet industry proposed the following hypotheses

$\mathbf{H}_{4 \mathbf{a}}$ : Perception of usefulness had a positive direct influence on attitude towards the use of large broadband ISPS.

$\mathbf{H}_{4 \mathrm{~b}}$ : Perception of benefits had a positive direct influence on attitude towards the use of small broadband ISPS.

H5a: The perception of ease of use has a positive direct influence on attitude towards the use of large broadband ISPs.

Hsb: The perception of ease of use has a positive direct influence on attitude towards the use of small broadband ISPS.

Empirical studies suggested that the technology acceptance model (TAM) helped to explain the acceptance of new information technologies (Zhu et al., 2012: 965), as well as the purchase forecast (Jang and Noh, 2011, pp. 584) and the usage. Previous studies showed a correlation between TAM in terms of perceived usefulness and intention. Lin, Shih and Sher (2007), Huh et al. (2009), Zhu et al. (2012), Chang et al. (2012), Nath et al. (2013) and Rauniar et al. (2014) revealed that perceived usefulness was positively correlated with purchase intention. On the other hand, Lin et al. (2011) and Bashir and Madhavaiah (2015) declared that perceived usefulness did not affect intention to use. While past research showing a relationship between TAM in the perceived ease of use and intention, such as Lin et al. (2007), found that the perceived ease of use was positively correlated with purchase intention. Chang et al. (2012) found that the perception of ease of use affected purchase intention. However, Bashir and Madhavaiah (2015) found that the perceived ease of use did not affect behavioral intention.

According to the unclear relationships, this research in the broadband internet industry context set the following hypotheses

$\mathbf{H}_{6 \mathbf{a}}$ : Perceived usefulness had a positive direct influence on the intention to use of large broadband ISPS.

Hob: Perceived usefulness had a positive direct influence on the intention to use of small broadband ISPS.

$\mathbf{H}_{7 \mathbf{a}}$ : Perceived ease of use had a positive direct influence on the intention to use of large broadband ISPS.

$\mathbf{H}_{7 \mathbf{b}}$ : Perceived ease of use had a positive direct influence on the intention to use of small broadband ISPS.

Many prior researches showing a correlation between attitude and intention to use, such as Huh et al. (2009) found that attitude affected behavioral intentions to use. Carlson and O'Cass (2010) found that consumer attitude positively influenced behavioral intentions. Lin et al. (2011) found that attitude to use affected behavioral intentions. Jang and Noh (2011) declared that attitude had a positive direct effect on repeat purchase intention. Zhu et al. (2012) found that user attitude influenced intention to use. Chang et al. (2012) revealed that attitude had an impact on purchase intention.

Al-Hujran et al. (2015) and Bashir and Madhavaiah (2015) claimed that attitude affected behavioral intentions. Mansour et al. (2016) illustrated that customer attitude had a positive effect on service intentions, including Rahi et al. (2017). Therefore, this research, in the context of the broadband internet industry developed the following hypotheses.

Hsa: Attitude had a positive direct influence on intention to use large broadband ISPS.

$\mathbf{H}_{\mathbf{8 b}}$ : Attitude had a positive direct influence on intention to use small broadband ISPS.

Nonetheless, experimental researches present no confirmation of the mediating impacts of attitude, perceived usefulness and perceived ease of use on intention to use of large and small broadband ISPs in Thailand. Accordingly, this study intends to examine the indirect effect of service quality and on intention to use broadband internet through attitude, perceived usefulness and perceived ease of use on intention to use as mediating factors (H9a, H9b, H10a, H10b, H11a and H11b).

H9: Service quality has an indirect influence on attitude towards the use of broadband ISPs.

$\mathbf{H}_{\mathbf{b}}$ : Service quality has an indirect influence on attitude towards the use of broadband ISPS.

$\mathbf{H}_{10 \mathrm{a}}$ : Service quality has an indirect influence on attitude towards the use of broadband internet from large broadband ISPS mediated by perceived usefulness.

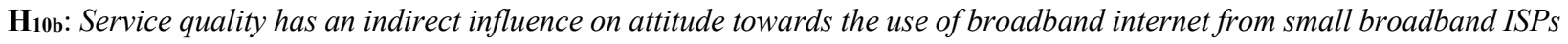
mediated by perceived usefulness.

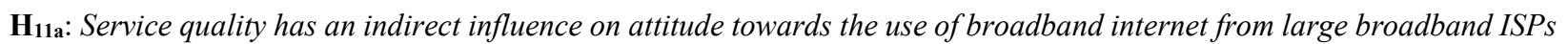
mediated by perceived ease of use.

H11b: Service quality has an indirect influence on attitude towards the use of broadband internet from small broadband ISPs mediated by perceived ease of use. 


\section{Methodology}

\subsection{Data collection methods}

In this research, the target population is people who have used broadband ISPs in Thailand. Three large companies consist of Advanced Info Services Public Company Limited (AIS), True Corporation Public Company Limited (TRUE) and Triple T Internet Company Limited (3BB). Two small companies consist of CAT Telecom Public Company Limited (CAT) and TOT Public Company Limited (TOT). The minimum required sample size should not be less than 200 for Structural Equation Modeling (SEM). At least 10 samples per question were analyzed to test the hypothesis. (Kline, 2011; Lacobucci, 2010). The researchers had a total of 35 questions in this research, so the number of samples to be used in this research should not be less than 350 samples to meet the requirement (Kline, 2011; Lacobucci, 2010). This research applied multi-stage sampling, which was ordered as follows.

Step 1: Cluster Sampling is divided into 2 groups according to the number of service users: large and small broadband ISPS in Thailand.

Step 2: Select a sample from each subgroup in order to get an appropriate number and cover demographic, providing equal opportunity for all broadband internet users. Then the researchers selected quota-based randomization by dividing the population into three groups, set the theoretical proportions 50-50 (Battaglia and Michael, 2008), respectively.

Samples were selected from 33.33\% of AIS, TRUE and 3BB broadband internet users. According to the standard of sample size, this research required 400 broadband internet users or not less than 350 people in large companies, (Kline, 2011; Lacobucci, 2010). The sampling can be calculated as follows.

Group of AIS broadband internet users: $\operatorname{AIS}(33.33 \%)=\frac{33.33}{100} \times 400=133$

Group of TRUE broadband internet users: $\operatorname{TRUE}(33.33 \%)=\frac{33.33}{100} \times 400=133$

Group of 3BB broadband internet users: $3 B B(33.33 \%)=\frac{33.33}{100} \times 400=133$

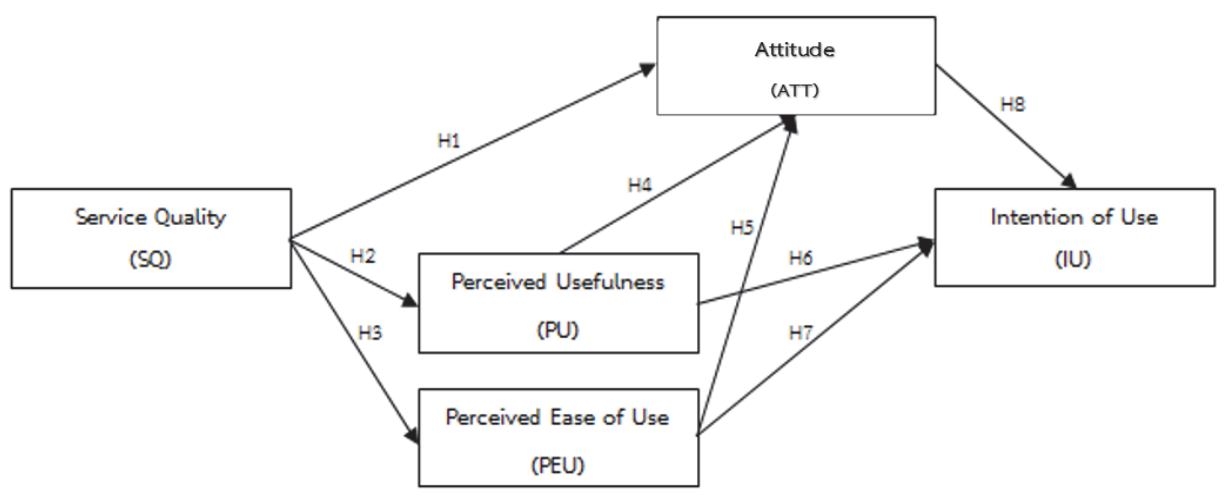

Fig. 1. Conceptual method

Subsequently, samples were selected from $50 \%$ of CAT and TOT broadband internet users. This study required a total of 400 small broadband internet users, not less than 350 people according to the standard criteria (Kline, 2011; Lacobucci, 2010). The sampling was calculated as follows,

Group of CAT broadband internet users: $C A T(50 \%)=\frac{50}{100} \times 400=200$

Group of TOT broadband internet users: $\operatorname{TOT}(50 \%)=\frac{50}{100} \times 400=200$

Table 1

Number of samples

\begin{tabular}{ccc}
\hline Group of broadband internet users & Company & Number of samples \\
\hline & AIS & 133 \\
Large size & TRUE & 133 \\
& $3 \mathrm{BB}$ & 133 \\
Small size & CAT & 200 \\
& TOT & 200 \\
\hline
\end{tabular}


It could be concluded that the sample selection from AIS, TRUE and 3BB broadband internet users, large companies, and the sample selection from the broadband Internet service users CAT and TOT, small companies and can be as shown in Table 1.

Step 3, which is the last step. Researchers selected a randomized sampling based on convenience sampling to reach the calculated number of samples in step 2.

\section{Measurement scale}

This research used questionnaires as a tool for data collection. Researchers set the Measurement Scale or questionnaire for each variable on the basis of literature review and related researches. Each question had a 5-level response (5-Point Scale), where 5 means strongly agree, up to 1 means strongly disagree. The measurements were as follows: To measure service quality of broadband internet service providers through a user attitude. The researchers used a tool called SERVQUAL (Zeithaml and Bitner, 1996; Namahoot \& Laohavichien, 2018), comprising 5 dimensions. 1) tangibility, 2) reliability, 3) responsiveness, 4) assurance and 5) empathy (Zeithaml \& Bitner, 1996; Namahoot \& Laohavichien, 2018). This part of the questionnaire consisted of 19 questions. To measure the attitude of broadband internet users, the researchers applied the questions of Nasri and Charfeddine (2012) and Namahoot and Laohavichien (2018), consisting of six questions for perceived usefulness. Researchers applied the questions of Nasri and Charfeddine (2012) and Namahoot and Laohavichien (2018), consisting of 4 questions for perceived ease of use. Finally, to measure the intention to use broadband internet users, researchers applied the questions of Nasri and Charfeddine (2012) and Namahoot and Laohavichien (2018), consisting of 3 questions for intention to use.

\section{Data analysis}

\subsection{Validity}

Analyzing the data prior to the actual data collection, researchers assessed the quality of questionnaires through validity and reliability checks. Therefore, to examine validity, researchers need to have a content validity test, with the index of itemobjective congruence (IOC). The consistency of each question must not be less than 0.67 (Parish et al., 2010). The steps are as follows: 1) Researchers asked the questions to three experts to verify completeness, accuracy and consistency according to the relevant theories, including wording. Then researchers take actions to make adjustments or modifications according to the expert's advice. After the checking, it was found that the value was not lower than 0.67 , all questions were considered standardized (Parish et al., 2010).

\subsection{Reliability}

Reliability was tested by handing revised questionnaires to people who used the broadband internet service of AIS, TRUE, 3BB, CAT, and TOT in Thailand. 30 samples were examined for the confidence by Cronbach's Alpha Coefficient. When Cronbach's alpha is more than 0.7 , all variables were considered to pass the standard (Choudhary et al., 2013). Therefore, the researchers used this question to collect the data. Analyzing the data after the actual data collection, researchers started with the report of demographic data using descriptive statistics including frequency and percentage values, to describe general information about the respondents. After that, the researchers revealed the data screening as follows: Step 1 The outlier of the data (outlier) with the Mahalanobis Distance method. The p-value must not be less than. $0.001(\mathrm{P}<0.001)$, therefore the data is not abnormal (Joo et al., 2012: 571; Vianello et al., 2010: 396; Beauchamp et al., 2005: 12). Step 2 checking the normality of the data with skewness and kurtosis, considering the skewness value must be in the range of -2.00 to 2.00 and the kurtosis must be in the range of -7.00 to 7.00 (Curran et al., 1996), the normal distribution data was assumed and the third step was the confidence check. Reliability and validity of a structure (construct validity) started with confidence. The reliability of Cronbach's alpha coefficient should not lower than 0.7 (Choudhary et al., 2013: 436; Carmeli et al., 2006: 81). Next examining the validity structure was checked by considering the factor loading of each component of the questionnaire (exploratory factor analysis). It must be greater than 0.40. Subsequently, hypothesis testing was performed by examining the measurement model starting with the confirmatory factor analysis (CFA). Then to check whether the observed variables were under the latent variables and to find out the more important observable variables. The researcher performed the harmonization analysis of the 1st and 2nd confirmatory factor analysis (CFA) models and checked the standardized factor loadings. The average variance extracted: AVE must be greater than 0.5 (Fornell \& Larcker, 1981). The convergent validity was considered from composite reliability (CR), it must be greater than the AVE (Hair et al., 2010). The discriminant validity, based on the AVE for each construct must be greater than the squared correlation involving the constructs (Bagozzi, 1993). Finally, the structural equation modeling (SEM) was considered by the Fit Index: $x 2 /$ df $<3$, RMSEA $<0.08$, CFI $>0.90$, IFI $>0.90$, TLI $>0.90, \mathrm{NFI}>0.90$ and $\mathrm{RMR}<.0 .05$ (Hair et al., 2010).

\section{Results}

Results of the validity analysis were derived from the contents validity measurement with the objective-to-question (IOC). The consistency of each question was found to be between 0.67 and 1.00 , which was considered to pass the benchmark (Parish et al., 2010). Results from try-out using the Cronbach method found that the confidence values were between 0.851 - 0.927, respectively, which were considered standardized (Choudhary et al., 2013).

\subsection{The results of analysis of demographic data with descriptive statistics}

Most of the respondents were female, 530 people, representing 58 percent, aged between 31-35 years, 280 people, representing 30.6 percent, having 461 people, 50.4 percent of whom had a bachelor's degree, with 382 people. Accounting for 41.78 percent of 
the occupation of government employees or company employees of 328 people, or 35.9 percent with an average monthly income of 40,000 baht, totaling 430 people, or 47 percent using the internet service during $21.01-11.30$ hours, 380 people, Accounting for 41.6 percent using the internet service 3-6 hours / day, there are 359 people, or 39.3 percent. The Internet was mainly used for searching 554 people, 60.6 percent, 474 people, 51.9 percent, and 534 people using 3BB, 58.4 percent.

\subsection{Data screening results}

Checking the outlier of the data (Outlier) by means of Mahalanobis Distance based on the p-value must not be less than 0.001 (P $<0.001$ ), the data is not abnormal (Joo et al., 2012: 571; Vianello et al., 2010: 396; Beauchamp et al., 2005: 12) found 534 and 380 sample data from large and small user groups, respectively. There was a low benchmark value (Hair et al., 2014), which was considered not anomalous data. Therefore, data can be analyzed in the next step. The results of examining the normal distribution of data (Normality) with skewness and kurtosis, there were values between -0.125 and 1.363 , and the skewness of each variable. If values between -5.590 and 2.880 indicated that the data was normally distributed. Reliability results were considered from Cronbach's alpha coefficient of samples. The confidence value is between $0.842-0.967$, considered to pass the standard (Choudhary et al., 2013). However, as examining the confidence of those who used broadband internet services of small companies, it was found that the tangible of the quality of service consisted of five questions that had an alpha coefficient of 0.631 , which was considered, less than the benchmark value (0.7). So, the researcher eliminated one question (item 1) and calculated the alpha coefficient again. The results showed that the alpha coefficient was 0.739 , which passed the standard. Questionnaires are reliable therefore these questions could be used to analyze the data further.

Table 2

Results of Reliability

\begin{tabular}{|c|c|c|c|}
\hline \multirow{2}{*}{ Dimension } & \multirow{2}{*}{ Items } & \multicolumn{2}{|c|}{ Cronbach Alpha } \\
\hline & & Large & Small \\
\hline \multirow[t]{5}{*}{$\begin{array}{l}\text { Service Quality } \\
\text { Tangible }\end{array}$} & The service staff dress politely & 0.82 & 0.80 \\
\hline & Building is clean, it is not crowded, providing adequate light, good ventilate & 0.85 & 0.79 \\
\hline & There are promotional materials or other additional documents with clear details. & 0.83 & 0.85 \\
\hline & Drinking water is provided while waiting for service. & 0.74 & 0.77 \\
\hline & There is a system for providing services such as having a queue card & 0.73 & 0.80 \\
\hline \multirow[t]{3}{*}{ Reliability } & Internet signal meets customer needs & 0.78 & 0.79 \\
\hline & Employees can recommend the applications to customers. & 0.83 & 0.77 \\
\hline & Corporate reputation and image are generally accepted. & 0.85 & 0.79 \\
\hline \multirow[t]{4}{*}{ Responsiveness } & Employees can solve problems for customers quickly. & 0.81 & 0.78 \\
\hline & Employees are always ready to provide service. & 0.85 & 0.87 \\
\hline & $\begin{array}{l}\text { When receiving an internet failure report from customers, staff will respond promptly within } 24 \\
\text { hours. }\end{array}$ & 0.82 & 0.84 \\
\hline & Staff can respond to the needs of customers in many ways. & 0.81 & 0.84 \\
\hline \multirow[t]{4}{*}{ Assurance } & Staff have knowledge, skills and operational expertise. & 0.82 & 0.79 \\
\hline & Staff can provide accurate and complete customer information. & 0.83 & 0.85 \\
\hline & Staff can solve problems immediately. & 0.85 & 0.84 \\
\hline & Staff have a trustworthy personality. & 0.81 & 0.78 \\
\hline \multirow[t]{3}{*}{ Empathy } & Staff greet, speak sweetly and they are polite. & 0.86 & 0.81 \\
\hline & Staff care about customers and have willing to help. & 0.88 & 0.86 \\
\hline & Staff are able to communicate and recognize customer needs. & 0.86 & 0.87 \\
\hline \multirow[t]{6}{*}{ Attitude } & The use of broadband internet service can reduce the cost of mobile internet fee. & 0.78 & 0.81 \\
\hline & The use of broadband internet service is more convenient in daily life. & 0.76 & 0.82 \\
\hline & The use of broadband internet service is beneficial. & 0.77 & 0.83 \\
\hline & The use of broadband internet service makes you feel enjoyable with the getting of updated news. & 0.86 & 0.84 \\
\hline & The use of broadband internet service makes you feel less stressful. & 0.88 & 0.82 \\
\hline & Using of broadband internet services makes you feel joyful. & 0.89 & 0.83 \\
\hline \multirow[t]{4}{*}{ Perceived Usefulness } & $\begin{array}{l}\text { The use of broadband internet service has resulted in the development cognitive benefits of } \\
\text { learning a foreign language. }\end{array}$ & 0.79 & 0.79 \\
\hline & The use of broadband internet service increases the opportunity to receive new information. & 0.84 & 0.81 \\
\hline & The use of broadband internet service increases the level of success in business. & 0.85 & 0.80 \\
\hline & The use of broadband internet service makes it easy to communicate long-distance with others. & 0.79 & 0.85 \\
\hline \multirow[t]{3}{*}{ Perceived Ease of Use } & Broadband internet makes it easy to find the information you are looking for. & 0.85 & 0.88 \\
\hline & Broadband internet makes it easier to send and receive information. & 0.87 & 0.89 \\
\hline & Broadband internet makes you find information that meets your interests. & 0.84 & 0.85 \\
\hline \multirow[t]{3}{*}{ Intention to use } & You intend to regularly use broadband internet. & 0.90 & 0.91 \\
\hline & You intend to continuously use the broadband internet service inthe future. & 0.86 & 0.88 \\
\hline & You will recommend others to use broadband internet service. & 0.88 & 0.82 \\
\hline
\end{tabular}

\subsection{Model analysis}

A model with full elements must consist of exogenous variables and endogenous variables. External and internal variables consist of latent variables and observed variables, they are divided into two important sub-models (Burnette and Williams, 2005). The results of the confirmation element analysis of the first and second confirmation in the measurement model showed that the model of users of small broadband internet providers was not empirically consistent. (It does not pass the Fit Indices). So, the researchers had adjusted the model of small group companies. Question 8, in the reliability variable of service quality 
construct had a standard component weight of 0.41 (less than 0.50), then was eliminated (Browne \& Cudeck, 1993, pp. 136162; Hair et al., 2010; Namahoot \& Laohavichien, 2018, pp. 256-276) and analyzed the model again. As a result, the consistency of the five-factor measurement models (service quality, attitude, perceived usefulness, perceived ease of use and intention to use) among broadband internet users of large and small companies were found. That the chi-square $(\mathrm{x} 2)=$ $1565.342,1038.119$, the statistical significance $(p$-value $)=0.000$, the degree of freedom $(\mathrm{df})=543,478$. The $\mathrm{p}$-value does not pass. Other statistics based on relative chi-square values $(\mathrm{x} 2 / \mathrm{df})=2.883,2.172, \mathrm{NFI}=0.912,864 \mathrm{RMSEA}=0.059,0.071$ $\mathrm{RMR}=0.026,0.034 \mathrm{CFI}=0.940,0.921 \mathrm{IFI}=0.940,0.922$ and $\mathrm{TLI}=.0 .935,0.913$, they were qualified (Browne \& Cudeck, 1993, pp. 136-162; Hair et al., 2010; Namahoot \& Laohavichien, 2018, pp. 256-276). It can be concluded that a confirmatory factor of the intention to use is consistent with the empirical data. In conclusion, service quality, attitude, perceived usefulness, perceived ease of use and intention to use had reliability. The results of the verification of standard component weights (Standardized factor loadings) Average Variance Extracted (AVE) are greater than 0.5 (Fornell \& Larcker, 1981) Convergent Validity based on CR is greater than AVE (Hair et al., 2010). Factor loadings of the measurement items, based on confirmatory factor analysis were shown in Table 3. The factor loading for all items exceeds the recommended level of 0.6 ( $p<0.001$ ). Therefore, dimension significance of each item converges towards an associated dimension, showing convergent validity.

Table 3

Results of the analysis of standard elements and validity values of large and small broadband ISPs

\begin{tabular}{lccccc}
\hline \multicolumn{1}{c}{ Latent variables } & \multicolumn{2}{c}{ Standard element weight } & \multicolumn{2}{c}{ CR } & AVE \\
\cline { 2 - 6 } & Large & Small & Large & Small & Large \\
\hline Attitude & $0.76-0.78$ & $0.81-0.84$ & 0.903 & 0.938 & 0.824 \\
Service Quality & $0.91-0.96$ & $0.88-0.97$ & 0.974 & 0.973 & 0.882 \\
Intention to use & $0.86-0.90$ & $0.82-0.91$ & 0.915 & 0.839 & 0.781 \\
Perceived Ease of Use & $0.84-0.87$ & $0.85-0.89$ & 0.888 & 0.885 & 0.665 \\
Perceived Usefulness & $0.79-0.85$ & $0.79-0.85$ & 0.907 & 0.907 & 0.725 \\
\hline
\end{tabular}

\subsection{Discriminant accuracy}

Discriminant Validity: AVE is greater than the square of the correlation coefficient between a pair (Bagozzi, 1993).

Discriminant validity is the degree to which the measures of different concepts are distinct. Discriminant validity can be examined by comparing the squared correlations between constructs and variance extracted for a construct. The analysis results show that the squared correlations for each construct are less than the variance extracted by the indicators measuring. Construct, as shown in Table 4 and 5, indicating that the measure has adequate discriminant validity.

Table 4

Discriminate validity of Large broadband ISPs

\begin{tabular}{|c|c|c|c|c|c|}
\hline \multirow[t]{2}{*}{ Construct } & \multicolumn{5}{|c|}{ Discriminate } \\
\hline & PEO & SQ & AT & IU & $\mathbf{P U}$ \\
\hline Perceived Ease of Use & 0.876 & & & & \\
\hline Service Quality & 0.862 & 0.957 & & & \\
\hline Attitude & 0.875 & 0.819 & 0.940 & & \\
\hline Intention to use & 0.766 & 0.902 & 0.869 & 0.859 & \\
\hline Perceived Usefulness & 0.890 & 0.951 & 0.909 & 0.856 & 0.811 \\
\hline
\end{tabular}

Table 5

Discriminate validity of Small broadband ISPs

\begin{tabular}{|c|c|c|c|c|c|}
\hline \multirow{2}{*}{ Construct } & \multicolumn{5}{|c|}{ Discriminate } \\
\hline & AT & SQ & IU & PEO & $\mathbf{P U}$ \\
\hline Attitude & 0.928 & & & & \\
\hline Service Quality & 0.914 & 0.939 & & & \\
\hline Intention to use & 0.886 & 0.828 & 0.884 & & \\
\hline Perceived Ease of Use & 0.789 & 0.779 & 0.800 & 0.817 & \\
\hline Perceived Usefulness & 0.874 & 0.807 & 0.833 & 0.816 & 0.852 \\
\hline
\end{tabular}

From Tables 4 and 5, it can be concluded that the latent variables of service quality, attitude, perceived usefulness, perceived ease of use and intention to use broadband internet users of large and small broadband ISPs had convergent validity. Every observable variable within each latent variable is well internally correlated and has discriminant validity. All observables variables correlate within the same latent variable more than they correlate with observable variables of other latent variables.

\subsection{Structural equation model analysis}

The results of analysis are composed of goodness of fit of the structural equation modeling (SEM), by statistics values for evaluating the fit of model and empirical data (Browne \& Cudeck, 1993, pp. 136-162; Hair et al., 2010; Namahoot \& Laohavichien, 2018, pp. 256-276). As shown in Fig. 2 and Fig. 3. 
Table 6

The goodness-of-fit indices of the structural equation model to the recommended threshold values

\begin{tabular}{|c|c|c|c|c|}
\hline \multirow{2}{*}{ Construct } & \multirow{2}{*}{ Threshold level } & \multicolumn{2}{|c|}{ Statistics } & \multirow{2}{*}{ Results } \\
\hline & & Large group & Small group & \\
\hline$\chi^{2} / \mathrm{df}$ & $<5$ & 3.144 & 2.310 & pass \\
\hline NFI & $\geq 0.80$ & 0.903 & 0.854 & pass \\
\hline IFI & $\geq 0.90$ & 0.931 & 0.912 & pass \\
\hline TLI & $\geq 0.80$ & 0.925 & 0.903 & pass \\
\hline CFI & $\geq 0.90$ & 0.931 & 0.911 & pass \\
\hline RMR & $\leq 0.05$ & 0.032 & 0.034 & pass \\
\hline RMSEA & $<0.08$ & 0.063 & 0.075 & pass \\
\hline
\end{tabular}

Remarks: * Hair et al., (2010)

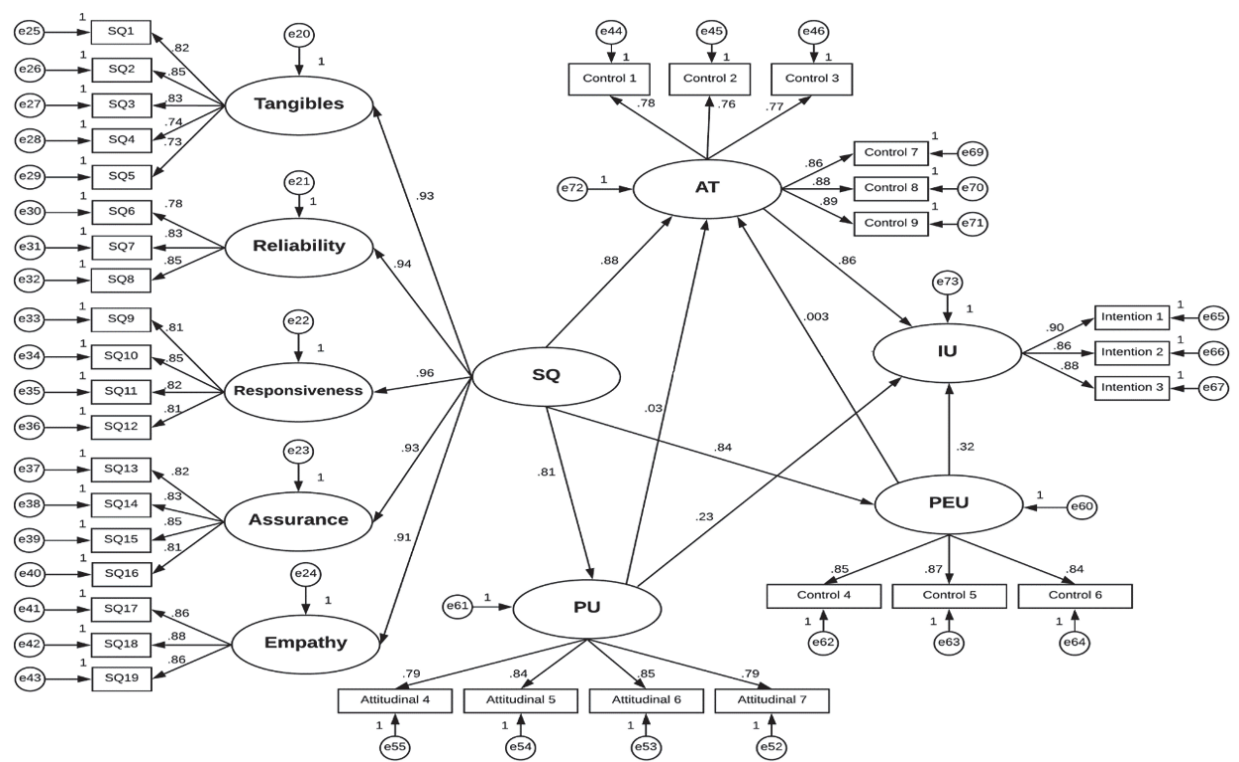

Fig. 2. The structural equation modelling analysis of large broadband internet users. (Large)

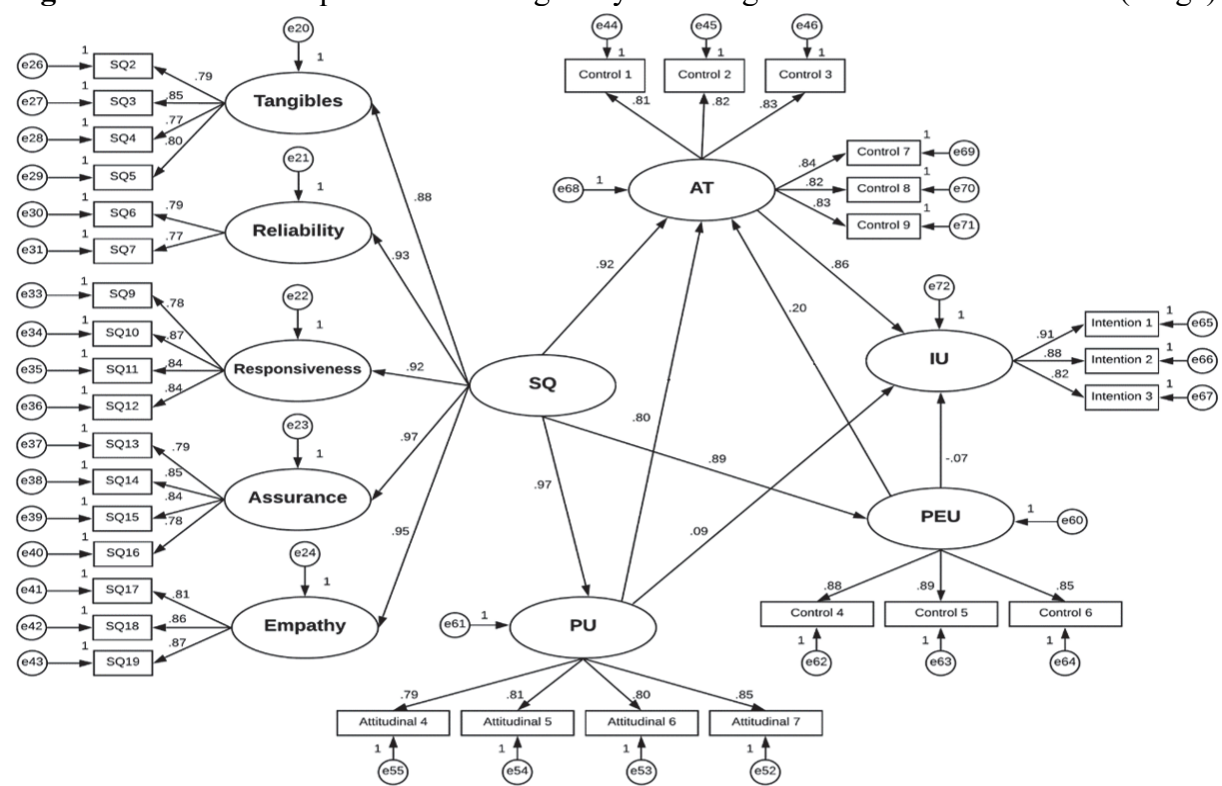

Fig. 3. Final analysis of structural model (Small) 


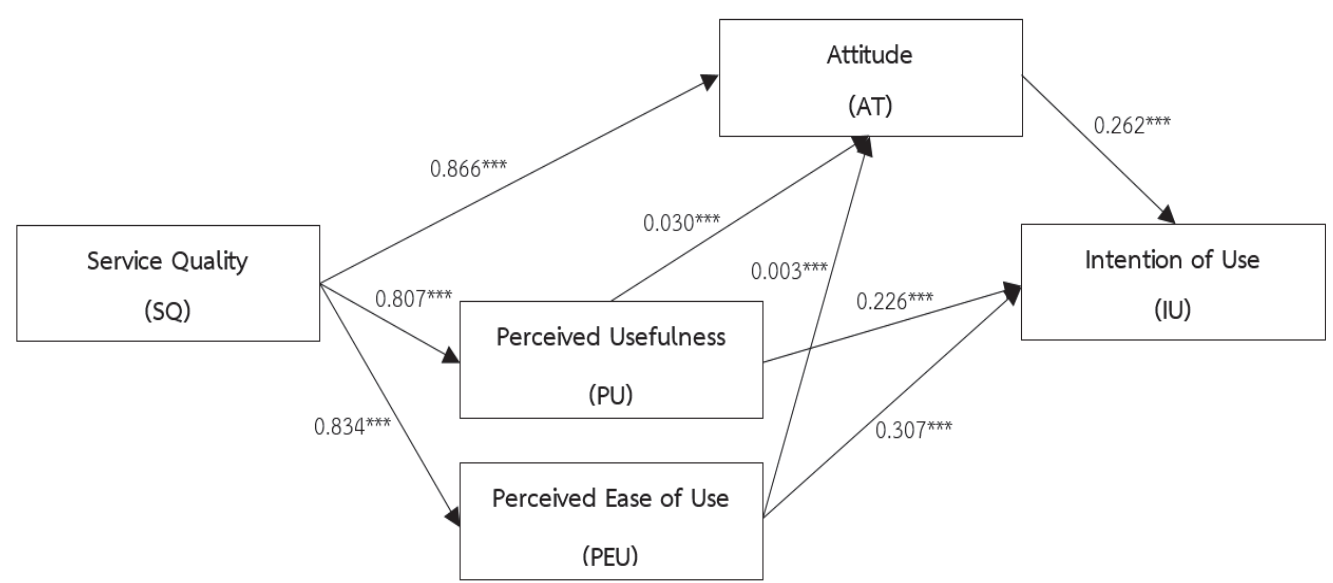

Fig. 4. Final analysis of structural model (Large)

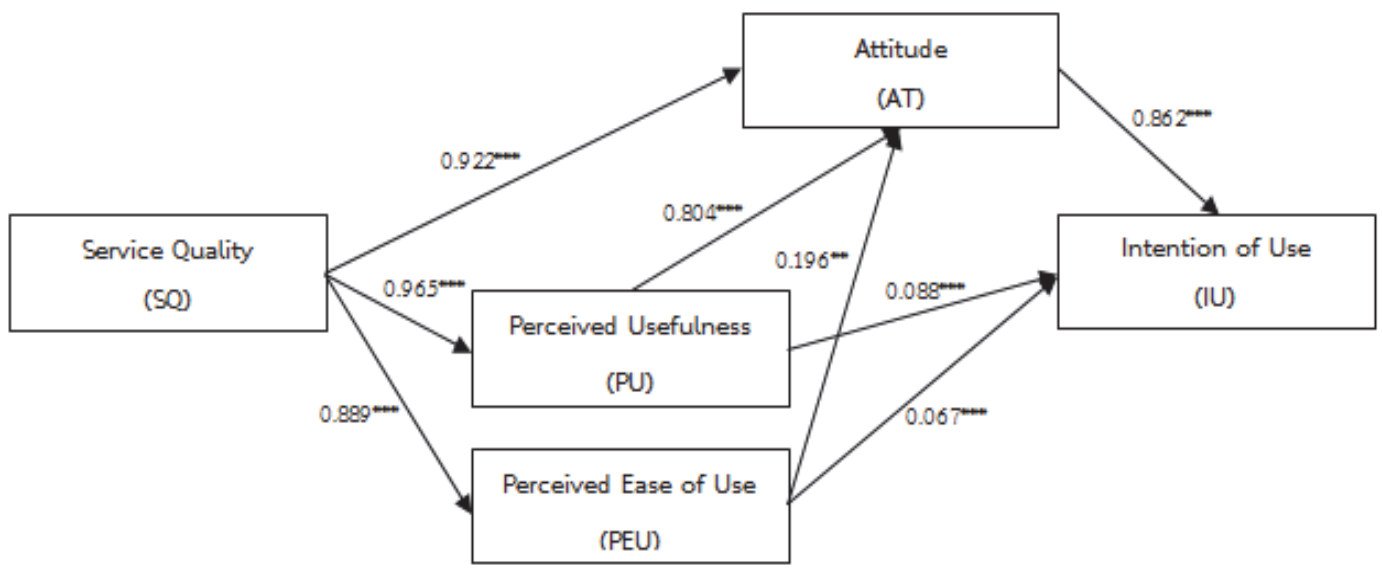

Table 6

Fig. 5. Final analysis of structural model (Small)

The results of hypotheses testing

\begin{tabular}{|c|c|c|c|c|c|c|c|}
\hline \multicolumn{5}{|c|}{ Hypotheses } & \multirow{2}{*}{\begin{tabular}{|c|} 
Direct effect \\
0.866
\end{tabular}} & \multirow{2}{*}{$\begin{array}{c}\text { Indirect effect } \\
-\end{array}$} & \multirow{2}{*}{$\begin{array}{l}\text { Results } \\
\text { Support }\end{array}$} \\
\hline H1a :SQ & $\longrightarrow$ & ATT & & & & & \\
\hline H1b :SQ & $\longrightarrow$ & ATT & & & 0.922 & - & Support \\
\hline H2a :SQ & $\longrightarrow$ & $\mathrm{PU}$ & & & 0.807 & - & Support \\
\hline H2b :SQ & $\longrightarrow$ & PU & & & 0.965 & - & Support \\
\hline H3a :SQ & $\longrightarrow$ & PEU & & & 0.834 & - & Support \\
\hline H3b :SQ & $\longrightarrow$ & PEU & & & 0.889 & - & Support \\
\hline H4a: PU & $\longrightarrow$ & ATT & & & 0.030 & - & Unsupported \\
\hline H4b :PU & $\longrightarrow$ & ATT & & & 0.804 & - & Support \\
\hline H5a :PEU & $\longrightarrow$ & ATT & & & 0.003 & - & Unsupported \\
\hline H5b :PEU & $\longrightarrow$ & ATT & & & 0.196 & - & Unsupported \\
\hline H6a :PU & $\longrightarrow$ & IU & & & 0.226 & - & Support \\
\hline H6b :PU & $\longrightarrow$ & IU & & & 0.088 & - & Unsupported \\
\hline H7a :PEU & $\longrightarrow$ & IU & & & 0.307 & - & Support \\
\hline H7b :PEU & $\longrightarrow$ & IU & & & 0.067 & - & Unsupported \\
\hline H8a :ATT & $\longrightarrow$ & IU & & & 0.262 & - & Support \\
\hline H8b :ATT & $\longrightarrow$ & $\mathrm{IU}$ & & & 0.862 & - & Support \\
\hline H9a :SQ & $\longrightarrow$ & ATT & $\longrightarrow$ & IU & - & 0.300 & Support \\
\hline H9b :SQ & $\longrightarrow$ & ATT & $\longrightarrow$ & $\mathrm{IU}$ & - & 0.415 & Support \\
\hline H10a :SQ & $\longrightarrow$ & $\mathrm{PU}$ & $\longrightarrow$ & $\mathrm{IU}$ & - & 0.190 & Support \\
\hline H10b :SQ & $\longrightarrow$ & $\mathrm{PU}$ & $\longrightarrow$ & $\mathrm{IU}$ & - & 0.479 & Support \\
\hline H11a :SQ & $\longrightarrow$ & PEU & $\longrightarrow$ & $\mathrm{IU}$ & - & 0.275 & Support \\
\hline H11b :SQ & $\longrightarrow$ & PEU & $\longrightarrow$ & IU & - & 0.044 & Unsupported \\
\hline
\end{tabular}

***at a level of significance of 0.05

Remark: Service Quality (SQ), Attitude (ATT), Perceived of Usefulness (PU), Perceived Ease of Use (PEU) 
The results of the hypothesis examination showed that service quality had a positive direct influence on attitude, perceived usefulness and perceived ease of use of broadband internet by large and small broadband ISPs. The results were statistically significant at a level of significance of $0.05(=0.866,0.922<0.05),(=0.807,0.965<0.05)$ and $(=0.834,0.889<0.05)$. Therefore, the hypotheses $1 \mathrm{ab}, 2 \mathrm{ab}$ and $3 \mathrm{ab}$ are accepted, respectively. However, the perceived usefulness did not have a positive influence on attitude. Consequently, hypothesis $4 \mathrm{a}$ was rejected, while the perceived usefulness had a positive influence on the attitude of small broadband ISPs. It was statistically significant at the $0.05(=0.804<0.05)$ level, hence the hypothesis $4 \mathrm{~b}$ was accepted. Perceived ease of use did not have a positive direct influence on attitude. Therefore, it rejected the hypothesis $5 \mathrm{ab}$. Perceived usefulness and perceived ease of use had a positive direct influence on the intention of use of users in large broadband ISPs. It was statistically significant at the 0.05 level $(=0.226<0.05)(=0.307<0.05)$, accordingly, the hypothesis $6 \mathrm{a}$ and $7 \mathrm{a}$ were accepted. On the other hand, perceived usefulness, perceived ease of use did not have a positive direct influence on the intentions of use of broadband internet or large broadband ISPs. Therefore, hypotheses $6 \mathrm{~b}$ and $7 \mathrm{~b}$ are rejected, but the attitude had a positive direct influence on the intentions of use of large broadband ISPs. It was statistically significant at the 0.05 level $(=0.262<0.05)(=0.862<0.05)$, as a result, the hypotheses $8 \mathrm{a}$ and $8 \mathrm{~b}$ were accepted. The results of analysis of indirect influences of mediators, namely perceived usefulness, perceived ease of use and attitudes showed that service quality had a positive direct influence on intention to use both large and small broadband ISPs. Perceived usefulness as a mediator was statistically significant at the 0.05 level $(=0.300,0.415<0.05),(=0.190,0.479,<0.05)$, so the hypotheses $9 \mathrm{ab}$ and $10 \mathrm{ab}$ were accepted, respectively. However perceived ease of use was found that the service quality had a positive direct influence on intention to use from large broadband ISPs. It was statistically significant at the 0.05 level $(=0.275,0.044<0.05$, consequently, the hypothesis 10a was accepted. The service quality had no positive direct influence on intentions of use of small broadband ISPs. Therefore, hypothesis $11 \mathrm{~b}$ was rejected.

\section{Conclusion and discussion}

There is a comparison of service quality affecting the technology acceptance on broadband internet use among large and small broadband ISPs by using structural equation analysis. The researcher concluded the discussion as follows:

First of all, service quality has a positive direct influence on attitude, perceived usefulness and perceived ease of use of broadband internet by both large and small broadband ISPs. If service quality is good, it will result in a positive influence on attitude, perceived usefulness and perceived ease of use in both large and small broadband ISPs. According to this research, the important findings are as follows:

For large broadband internet users, Assurance is one of the key factors that users perceive the most important: 1) Staff can provide accurate and complete customer information; 2) Staff can solve problems immediately. Secondly, empathy is another factor in service quality; 1) Staff are able to communicate and recognize customer needs; 2) Staff care about customers and are willing to help.

For small broadband internet providers, responsiveness is the main factor that users perceive the most important; 1) Staff are always ready to provide service; 2) When receiving customer reports about internet problems, a staff will respond promptly within 24 hours. Secondly, reliability is concerned, 1) Corporate reputation and image are generally accepted; 2) Staff can provide usage guides to customers. These are crucial elements of service quality for both large and small broadband ISPs Consequently the attitude, perceived of usefulness and perceived ease of use broadband internet will also be improved.

Therefore, large broadband ISPs should develop the service quality, particularly assurance. For example, developing employee skills are needed to provide accurate and complete information to users. They must be able to solve problems and obstacles reported by the service users. According to the research, it should also develop the service quality, especially empathy. For example, staff should have skills to know the needs of users. They must communicate well, pay attention and provide assistance to users with a service mind.

The small broadband ISPs should improve the service quality, apparently responsiveness, such as prompt service availability. It should also improve the service quality, specifically reliability. In case of any problem with the internet, prompt resolution must be available.

Companies need to build the company's reputation and image to be recognized among service users. It generally links to the research of Jang and Noh (2011). They claimed that customer service was essential in a Korean IPTV service. Owing to, the smaller service providers lack support personnel. As the small company is growing and expanding, it cannot afford immediate response. This can damage a reputation in the service as well. Unlike large broadband ISPs, users have confidence in the reputation of the organizations. However, they still need to improve the communication and user training skills for employees.

Secondly, perceived usefulness has a positive influence on small broadband ISPs' attitudes. The perceived usefulness does not have a positive influence on the attitude of the large broadband ISPs. It means that smaller broadband ISPs should increase perceived usefulness, resulting in a more positive attitude towards their use of broadband internet service. Unlike large broadband ISPs, no matter perceived usefulness are greater or lesser, it has no influence on their attitudes. Important findings reveal that perceived usefulness is one of the most important factors among small internet broadband users: 1) the use of broadband internet service makes it easy to communicate with other people; 2) the use of broadband internet service increases the opportunity to receive new information. Perceived ease of use does not have a positive direct influence on the attitude of both large and small service providers. If there is an increase or decrease in the perceived ease of use, it does not result in a better or less favorable attitude in both large and small broadband ISPs. 
Although for large internet broadband ISPs, perceived usefulness and perceived ease of use do not influence attitudes towards using the service. It is possible that since the organization is a trustworthy organization and has a good reputation for providing services, it creates trust in users with a positive attitude in using the service. This will create perceived usefulness because users can use it easily. Therefore, the organization should continuously develop and improve the customer retention. The results of this study differ from the ones conducted with traditional TAM research. However, research results are similar to previous studies of Jang et al., 2011. Furthermore, research results are identical to expanded TAM (Ha \& Stoel, 2009; Shin, 2009). Ha and Stoel (2009) examined user adoption of on-line shopping, results showed that the perceived ease of use did not have a positive effect on attitude. Jung et al. (2009) proposed that perceived ease of use unexpectedly had no influence on perceived usefulness. Consequently, it indicates that perceived ease of use played a trivial role in the extended TAM.

Small internet broadband ISPs should develop a system to meet the needs of service users and attract users. They should provide high speed internet with ease of use. They also need to expand the internet network covering all areas and increase the stability of internet connection. Thereby users can communicate clearly and continuously. It is consistent with the research conducted by Mansour et al., 2014. They investigated consumer attitude and behavioral intention towards internet banking adoption in India. The study showed that customers' attitude toward various bank technologies was not the same and was influenced by different factors. The results revealed that bank customers who were users of ATMs were influenced by its convenience, ease of use and service quality, whereas credibility was not seen as a significant driver. Mobile users were found to be influenced more by perceived usefulness and ease of use and service quality, whereas internet customers were influenced by perceived usefulness and ease of use and credibility of the systems. Under the three models, attitude emerged as a fully mediating factor for customers' behavioral intentions.

Thirdly, perceived usefulness and perceived ease of use have a positive direct influence on the intentions of use among large internet broadband users. Consequently, large internet broadband ISPs should increase perceived usefulness and ease of use. It creates an intention to use internet broadband service. From this research, the important findings were as follows:

Among large internet broadband users, perceived usefulness is one of the most important factors: 1) the use of internet broadband service makes it easy to communicate with other people; Ease of use is the most important factor for consumers. 1) Internet broadband makes it easier to send and receive information. 2) Broadband Internet makes it easy to find the information you need.

Among large internet broadband users, perceived usefulness and perceived ease of use do not have a positive direct influence on the intentions of use of smaller companies. The increasing or decreasing level of perceived usefulness and perceived ease of use do not affect the intention of the internet access.

At the same time, attitude has a positive direct influence on the broadband internet intentions of use. If the users have a positive attitude, it will result in the intention of using the broadband internet in both large and small broadband ISPs. According to this research, important findings are obtained.

Among large internet users 1) Broadband internet provides learning experience and social exchange of ideas. 2) Broadband internet facilities can link communication and knowledge. Among small users of broadband internet service 1) You have knowledge and understanding about broadband internet 2) Broadband internet provides learning experience and social exchange of ideas. Therefore, large broadband ISPs should maximize the benefits for users, such as make the use of broadband Internet service easy to communicate with others. Internet providers should improve and add new communication channels. This result is similar to the finding reported by Bashir and Madhavaiah (2015). Thus it implies that banks should promote internet banking services (IBS) by presenting its usefulness, user-friendliness and other benefits of IBS to consumers. Consequently, they develop positive attitudes towards using Internet banking. Rauniar et al. (2014) found that perceived usefulness and intention to use had the positive relationship with the intention to use and attitude. These three hypotheses reflect that successive social media usage which is the result of intention to use at the earlier usage. These three hypotheses are supported by the Facebook data, helping to validate the TAM model in the context of social media. Designers and developers of social media sites, applications, and pages should focus on how to create value for the social media users. If the users achieve their goals and objectives, these benefits are experienced, it translates into a positive attitude and intention to revisit the site in future. In order to be effective external communication, social media managers should ensure that an average user's utility is enhanced during the user's engagement at the social media site. Managers should keep in mind that a useful experience is important for a long term relationship and engagement. Users form a positive intention, creating perceived usefulness for targeted social media audiences. The value proposition serves the explicit need of the user. For example, a social media advertisement campaign should ensure that the advertisement is considered valuable enough for the targeted social media users. Therefore, it sets a positive intention to continue coming back in the future, or to create a buzz among the user's CRM.

In addition, the broadband ISPs should improve their services to make the internet easier to use, convenient and fast. For example, increase the download and upload speed, let the users use it easily, including the stability of the internet while using the service However, the service providers should provide information to support functions that users can easily find the information needed. These findings are consistent with the research of Bashir and Madhavaiah (2015) Al-Hujran et al. (2015) Mansour et al. (2016) Rahi et al. (2017) Li et al. (2017). They found that broadband ISPs should make their users realize the usefulness, user-friendliness and other benefits of services, so that users develop positive attitudes to continue using the service. In contrast, Jang and Noh (2011) discovered that perceived ease of use was not a very important factor. It is possible that the users get used to the service so they do not feel the hassle. In terms of attitude, it can be concluded that large broadband internet service providers should develop services that can result in a positive attitude for users to use, such as creating a 
service through learning. Exchange of experiences and social exchange of ideas along with a function will help linking communication with knowledge. Small broadband ISPs should focus on building knowledge and understanding how the service will lead to creating learning experience and exchange of ideas in social networks.

The role of perceived usefulness, perceived ease of use and attitude as mediating variables in this research showed that large broadband ISPs pay most attention to attitude $(=0.300)$ According to the study, the mediator variables of this research, perceived usefulness, perceived ease of use made an important finding. Large internet broadband users pay the most attention to attitude transmission $(=0.300)$. Subsequently, they focus on perceived ease of use $(=0.275)$ and perceived usefulness respectively $(=0.190)$. If the system has a good quality of service, it will result in a positive attitude. Perceived ease of use and perceived usefulness have impact on the intention to use. Users of small broadband ISPs view perceived usefulness as the most important variables $(=0.479)$, followed by attitude $(=0.415)$. It means that if the system has good service quality, it will have an effect on perceived usefulness, thus resulting in the intention to use the broadband internet. Therefore, the large broadband ISPs should focus on improving the quality of their services, especially in the areas of employee skills such as communicating with users. They should provide knowledge and correct information. They should have a willingness to assist in customer service and the readiness to help solve any problems immediately. These will create good attitudes towards service users, resulting in the intention to continue to serve the broadband internet.

As for the small broadband ISPs, they should focus on the quality of their service, especially responsiveness and reliability. The organization must have training to educate employees in the preparation of service. Particularly basic knowledge that can solve basic problems, if there is an internet connection failure, which can quickly contact staff within 24 hours. However, since it is a small broadband ISPs, building a reputation and corporate image is important, so a strategy for building a reputation and corporate image should be established, such as organizing social events. Marketing events to promote products, services, will give the consumer an appreciation of the benefits of using the service, and intention to use the broadband Internet.

\section{Theoretical suggestion}

In terms of theory building, this study suggests a new direction for technology acceptance research by presenting an integrated model of the determinants of adoption and use. The model develops a new theory by building new variables in an integration of TAM and TPB, and applying them to a new context. It is worthy to note that the new variables specific to the online environment, included in this research, attitude, perceived usefulness, perceived ease of use, are compatible with the TAM and TPB variables. While conventional consumer behavior is well-documented by economic and marketing theories, research has supported the importance of technology-related variables in predicting online consumer behavior (Jarvenpaa et al., 1999; McKnight et al., 1998; Pavlou, 2003). Many previous studies investigated intention to use models. Bashir and Madhavaiah (2015) found that the overall explanatory power of the modified structural model had an R2 of 66 percent for intention to use internet banking in India, and an R2 of 59 percent for attitude towards IBS. Also, the TAM beliefs PU and PEU have an R2 of 68 per cent and 57 percent However, this research shows that three mediator variables: attitude, perceived usefulness and perceived ease of use, are able to increase the model's forecasting and explain the relationship of broadband internet use. From this study, it can be concluded that service quality, attitude, perceived usefulness, perceived ease of use can explain $78.40 \%$ and $76.20 \%$ of the changes in the intention to use broadband internet.

\section{Practical recommendation}

From the results of this comparative study of service quality affecting technology acceptance of broadband internet service from large and small broadband ISPs, it presents that the quality of service is still a major factor. This indicates that broadband ISPs who wish to develop services to increase the number of customers, need to work align with consumer behavior trends. There are 3 main areas as follows.

\section{For large broadband internet service providers}

Broadband ISPs should improve the service quality, particularly, assurance and empathy. They need to develop staff skills to be able to provide accurate and complete information to users, along with developing their employees to have skills and abilities to solve problems. Employees should concentrate on the needs of the service users, fully understand, pay special attention to them and have willingness to help.

Broadband ISPs should develop their stability of long-distance connections. The Internet should be fast and easy to connect. Therefore, users can exchange updated information with others.

Broadband ISPs should improve the functions of information search. Companies should always send fresh news to users through modern channels. They should support service delivery through learning exchange experience and social exchange of ideas. Furthermore, broadband ISPs should facilitate users to access the source of knowledge.

\section{For small broadband internet service providers}

Small broadband ISPs should improve the quality of service, responsiveness and reliability. They need to provide instant service availability, especially internet failure, they must be available to solve the problem as quickly as possible. It will strengthen a reputation and build the positive image of the organization to be accepted by users. Small broadband ISPs should develop long distance communication services by improving the internet signal to control all areas, increase the speed of the internet, and make the signal stable. Consequently, users can have convenient communication. Surfers can 
continuously spend long time on the internet this can meet the needs of the users and to attract the future users. Moreover, broadband ISPs should focus more on training and offering service manual guidance. As users are familiar with the internet they will participate in social media and this can encourage them to exchange of ideas.

\section{Limitations and future research directions}

This research is also subject to reasonable limitations and shortcomings. Considering this, the research has identified the following limitations and directions for future research. Firstly, this research employed a non-probability based convenient sampling method to collect the data from a few cities and via personally visiting places which mainly included universities. Such an approach is not uncommon and has been widely utilised in previous studies on adoption of a variety of technology. Respondents in the sample were supposed to be able to access smartphones. Non-probability sampling should not have made a substantial impact on the results of this study. However, it would be useful for future studies to employ probability sampling so a comparison can be made with non-probability sampling. Secondly, the majority of the respondents for this research were conducted among Thai people who were computer and internet literacy. The questionnaire was in Thailand language only. In future, data can be collected by a method which allows people from different language and education levels to participate. Third, this research focused only on a quantitative approach. The in-depth view of consumers should be explored more on a qualitative approach. Due to time and resources constraints in depth research, a mixed method approach was not conducted. However, it can reveal more perspective with a mixed method approach. Future studies can utilise a mixed method approach for further understanding. Finally, this research measure uses behaviour through self-reported usage scales. Future studies should try to collect and analyse actual usage data.

\section{References}

Ajzen, I. (1991). The theory of planned behavior. Organizational Behavior and Human Decision Processes. 50, 179-211.

Al-Hujran, O., Al-Debei, M. M., Chatfield, A., \& Migdadi, M. (2015). The imperative of influencing citizen attitude toward e-government adoption and use. Computers in Human Behavior, 53, 189-203.

Bagozzi, R. P. (1993). Assessing construct validity in personality research: Applications to measures of self-esteem. Journal of Research in Personality, 27(1), 49-87.

Bashir, I., \& Madhavaiah, C. (2015). Consumer attitude and behavioural intention towards Internet banking adoption in India. Journal of Indian Business Research, 7(1), 67-102.

Battaglia., \& Michael, P. (2008). Nonprobability Sampling. In P. Lavrakas (Ed.). Encyclopedia of Survey Research Methods, SAGE. 524527.

Beauchamp, M. R., Bray, S. R., Eys, M. A., \& Carron, A. V. (2005). Leadership Behaviors and Multidimensional Role Ambiguity Perceptions in Team Sports. Small Group Research, 36(1), 5-20.

Boisvert, J., \& Ashill, N. J. (2011). How brand innovativeness and quality impact attitude toward new service line extensions: the moderating role of consumer involvement. Journal of Services Marketing, 25(7), 517-527.

Browne, M. W., \& Cudeck, R. (1993). Alternative ways of assessing model fit. In K. A. Bollen and J. S. Long (Eds.). Testing structural equation models. Newbury Park, CA: Sage. 136-162.

Burnette, J. L., \& Williams, L. J. (2005). Structural equation modeling (SEM): An introduction to basic techniques and advanced issues. Research in Organizations: Foundations and Methods of Inquiry, San Francisco, CA: Berrett-Koehler. 143-160.

Carlson, J., \& O'Cass, A. (2010). Exploring the relationships between e-service quality, satisfaction, attitudes and behaviours in contentdriven e-service web sites. Journal of Services Marketing, 24 (2), 112-127.

Carmeli, A., Meitar, R., \& Weisberg, J. (2006). Self-Leadership Skills and Innovative Behavior at Work. International Journal of Manpower, 27(1), 75-90.

Chang, K.-C., Chen, M.-C., Hsu, C.-L., \& Kuo, N.-T. (2012). Integrating loss aversion into a technology acceptance model to assess the relationship between website quality and website user's behavioural intentions. Total Quality Management, 23(8), 913-930.

Choudhary, A., Akhtar, S., \& Arshad, Z. (2013). Impact of Transformational Servant Leadership on Organizational Performance: A Comparative Analysis. Journal of Business Ethics, Springer, 116(2), 433-440.

Curran, P. J., West, S. G., \& Finch, G. F. (1996). The robustness of test statistics to nonnormality and specification error in confirmatory factor analysis. Psychological Methods, 1, 16-29.

Davis, F. D. (1993). User acceptance of information technology: system characteristics, user perceptions and behavioral impacts. International Journal of Man-Machine Studies, 38(3), 475-487.

Davis, F. D. (1989). Perceived usefulness, perceived ease of use, and user acceptance of information technology. MIS Quarterly, 13(3), 319-340.

Electronic Transactions Development Agency, Ministry of Digital Economy and Society. (2020). Thailand Internet User Behavior 2019.

Electronic Transactions Development Agency, Ministry of Digital Economy and Society. (In Thai)

Fornell, C., \& Larcker, D. F. (1981). Evaluating Structural Equation Models with Unobservable Variables and Measurement Error. Journal of Marketing Research, 19, 39- 50.

Ha, S., \& Stoel, L. (2009). Consumer e-shopping acceptance: Antecedents in a technology acceptance model. Journal of Business Research, $62,565-571$.

Hair, J. F., Black, W. C., Babin, B. J., \& Anderson, R. E. (2010). Multivariate Data Analysis: A Global Perspectives. 7th Edition, Pearson, Prentice Hall, New York.

Hair, Joe. F., Marko, S., Lucas, H., \& Kuppelwieser, V. G. (2014). Partial Least Squares Structural Equation Modeling (PLS-SEM): An Emerging Tool in Business Research. European Business Review, 26(2), 106-121.

Hassanein, K., \& Head, M. (2007). Manipulating perceived social presence through the web interface and its impact on attitude towards online shopping. International Journal Human-Computer Studies, 65, 689-708. 
Huh, H. J., Kim, T. T., \& Law, R. (2009). A comparison of competing theoretical models for understanding acceptance behavior of information systems in upscale hotels. International Journal of Hospitality Management, 28, 121-134.

Jang, H. Y., \& Noh, M. J. (2011). Customer acceptance of IPTV service quality. International Journal of Information Management. 31, $582-592$.

Jarvenpaa, S. L., Tractinsky, N., \& Saarinen, L. (1999). Consumer Trust in an Internet Store: A Cross-Cultural Validation. Journal of Computer-Mediated Communication, 5(2).

Joo, B. K., Yoon, H. J., \& Jeung, C. W. (2012). The Effects of Core Self-Evaluations and Transformational Leadership on Organizational Commitment. Leadership and Organization Development Journal, 33(6), 564-582.

Jung, Y., Perez-Mira, B., \& Wiley, S. (2009). Consumer adoption of mobile TV: Examining psychological flow and media content. Computers in Human Behavior, 25(1), 123-129.

Kline, R. B. (2011). Principles and practice of structural equation modeling. 3rd ed. New York: Guilford press.

Lacobucci, D. (2010). Structural equations modelling: Fit Indices, sample size, and advanced topics. Journal of Consumer Psychology, 20 , 90-98.

Li, R., Chung, T. -L., \& Fiore, A. M. (2017). Factors affecting current users' attitude towards e-auctions in China: An extended TAM study. Journal of Retailing and Consumer Services, 34, 19-29.

Lin, C. -H., Shih, H. -Y., \& Sher, P. J. (2007). Integrating technology readiness into technology acceptance: The TRAM model. Psychology and Marketing, 24(7), 641-657.

Lin, F., Fofanah, S. S., \& Liang, D. (2011). Assessing citizen adoption of e-Government initiatives in Gambia: A validation of the technology acceptance model in information systems success. Government Information Quarterly, 28, 271-279.

Mansour, N., EL-Deghaidy, H., Al-Shamrani, S., \& Aldahmash, A. (2014). Rethinking the theory and practice of continuing professional development: Science teachers' perspectives. Research in Science Education, 44 (6), 949-973.

Mansour, I. H. F., Eljelly, A. M. A., \& Abdullah, A. M. A. (2016). Consumers' attitude towards e-banking services in Islamic banks: the case of Sudan. Review of International Business and Strategy, 26(2), 244-260.

McKnight, D. H., Cummings, L. L., \& Chervany, N. L. (1998). Initial Trust Formation in New Organizational Relationships. The Academy of Management Review, 23(3), 473-490.

Namahoot, K. S., \& Laohavichien, T. (2018). Assessing the intentions to use internet banking: The role of perceived risk and trust as mediating factors. International Journal of Bank Marketing, 36(2), 256-276.

Nasri, W., \& Charfeddine, L. (2012). Factors affecting the adoption of internet banking in Tunisia: An integration theory of acceptance model and theory of planned behavior. Journal of High Technology Management Research, 23, 1-14.

Nath, R., Bhal, K. T., \& Kapoor, G. T. (2013). Factors influencing IT Adoption by Bank Employees: An Extended TAM Approach. VIKALPA, 38(4), 83-96.

Parasuraman, A., Zeithaml, V. A., \& Berry, L. L. (1985). A conceptual model of service quality and its implications for future research, Journal of Marketing. 49(1), 41-50.

Parasuraman, A., Zeithaml, V. A., \& Berry, L. L. (1988). SERVQUAL: A multiple-item scale for measuring consumer perceptions of service quality. Journal of Retailing, 64(1), 12-40.

Parish, T., Baghurst, T., \& Turner, R. (2010). Becoming Competitive Amateur Bodybuilders: Identification of Contributors. Psychology of Men \& Masculinity, 11(2), 152-159.

Pavlou, P. A. (2003). Consumer acceptance of electronic commerce: Integrating trust and risk with the technology acceptance model. International Journal of Electronic Commerce, 7(3), 101-134.

Pikkarainen, T., Pikkarainen, K., Karjaluoto, H., \& Pahnila, S. (2004). Consumer acceptance of online banking: an extension of the technology acceptance model. Internet Research, 14 (3), 224-235.

Rahi, S., Ghani, M. A., \& Alnaser, F. M. (2017). Predicting customer's intentions to use internet banking: the role of technology acceptance model (TAM) in e-banking. Management Science Letters, 7, 513-524.

Rauniar, R., Rawski, G., Yang, J., \& Johnson, B. (2014). Technology acceptance model (TAM) and social media usage: an empirical study on Facebook. Journal of Enterprise Information Management, 27 (1), 6-30.

Seth, N., Deshmukh, S.G., \& Vrat, P. (2005). Service quality models: a review. International Journal of Quality and Reliability Management, 22(9), 913-949.

Shin, D. H. (2009). Towards an understanding of the consumer acceptance of mobile wallet. Computers in Human Behaviour, 25, 13431354.

Venkatesh, V., \& Davis, F. D. (2000). A theoretical extension of the technology acceptance model: four longitudinal field studies. Management Science, 46(2), 186-204.

Vianello, M., Galliania, E. M., \& Haidt, J. (2010). Elevation at Work: The Effects of Leaders' Moral Excellence. The Journal of Positive Psychology, 5(5), 390-411.

World Health Organization. (2020). Coronavirus. available at: https://www.who.int/thailand/health-topics/coronavirus (accessed 3 April 2020). (In Thai)

Zeithaml, V. A. (1988). Consumer Perceptions of Price, Quality, and Value: A Means-End Model and Synthesis of Evidence. Journal of Marketing, 52, 2-22.

Zeithaml, V. A., \& Bitner, M. J. (1996). Service Marketing: Customer Focus Across the Firm. 2rd ed. McGraw-Hill.

Zhu, D. -S., Lin, T. C. -T., \& Hsu, Y. -C. (2012). Using the technology acceptance model to evaluate user attitude and intention of use for online games. Total Quality Management, 23(8), 965-980.

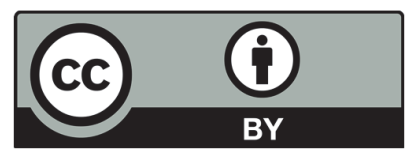

(C) 2021 by the authors; licensee Growing Science, Canada. This is an open access article distributed under the terms and conditions of the Creative Commons Attribution (CC-BY) license (http://creativecommons.org/licenses/by/4.0/). 